JOM: The Journal publishes peer-reviewed technical articles covering the full range of minerals, metals, and materials. TMS members receive free electronic access to the full library of TMS journals, including JOM. For the full JOM Editorial Calendar, visit wwww.tms.org/EditorialCalendar.

Review the technical topics included in the current issue of JOM: The Journal here, and then go to wwww.tms.org/JOM to log in and access technical journal articles on the Springer website.

\title{
MARCH 2022
}

\section{Additive Manufacturing with Light Alloys}

Scope: Additive manufacturing (AM) with light alloys, especially Al-based alloys, is both desirable and challenging. This is a rapidly growing research field with a clear impact on future manufacturing. Papers are presented on the development and adaptation of AM Al-based alloys, development of an AM process for mitigating technological issues such as hot and cold cracking, porosity, grain growth texture and compositional segregation, post-processing of AM parts, and advanced characterization and testing of AM parts.

Editors: Dmitry Eskin, Brunel University London Sponsor: Aluminum Committee

\section{Advanced Functional and Structural Thin Films and Coatings}

Scope: This special topic encompasses all aspects of advanced thin films and nanomaterials for modern optical, photonic, and electronic devices with applications in photovoltaics, sensing, and display technologies. It also addresses coating technologies and surface structuring for tools, as well as multifunctional biomaterials, innovative approaches to new concepts, and applications.

Editors: Ramana Chintalapalle, University of Texas at El Paso; Adele Carrado, Strasbourg University; Gerald Ferblantier, Strasbourg University; Karine Mougin, CNRS - IS2M; Heinz Palkowski, Clausthal University of Technology; and Nuggehalli M. Ravindra, New Jersey Institute of Technology

Sponsor: Thin Films and Interfaces Committee

\section{Decarbonization of \\ Pyrometallurgical Processes}

Scope: Pyrometallurgical processes require energy to heat the feed material up to the temperature required for reactions and phase separation to occur. Additionally, pyrometallurgical processes can also require reductants for the desired reactions to proceed. This energy and reductant can be derived from a variety of sources, with hydrocarbons commonly used. This topic focuses on techniques and technology to prevent or significantly reduce $\mathrm{CO}_{2}$ emissions.
Editors: Stuart Nicol, Glencore Technology, and Akbar Rhamdhani, Swinburne University of Technology Sponsor: Pyrometallurgy Committee

Powder Metallurgy of Non-Ferrous Metals: Striving Toward Technology Advancement Scope: Papers are presented exploring topics such as: (i) powder processing of light and reactive metals, high entropy alloys, and functionally graded materials and composites, (ii) recent advances in powder consolidation processes, e.g., spark plasma and microwave sintering, powder forging and extrusion, and cold spray forming, (iii) manufacturability investigations, novel process development and robustness, and (iv) modelling and simulation. Editors: David Yan, San Jose State University, and Kathy Lu, Virginia Polytechnic Institute and State University

Sponsor: Powder Materials Committee

\section{Recovery of Rare Earth and Critical Metals from Unconventional Sources}

Scope: This topic presents submissions on science discoveries and emerging technologies that enable sustainable extraction, processing, and separation of rare earths and other co-product metals from unconventional sources, including but not limited to mine tailings, acid drainage, coal ash, and oil field brines.

Editors: Chukwunwike Iloeje, Argonne National Laboratory; Joseph Hamuyuni, Metso Outotec; Fiseha Tesfaye, Åbo Akademi University; and Alexandra Anderson, Gopher Resource

Sponsor: Process Technology and Modeling Committee, Energy Committee, and Recycling and Environmental Technologies Committee

\section{Solid Freeform Fabrication 2021}

Scope: The Solid Freeform Fabrication Symposium is a leading research conference dealing with all aspects of additive manufacturing. Selected papers from the conference will be invited and published on this topic. Editors: David Bourell, University of Texas at Austin Sponsor: Invited 